\title{
Acoustic communication in insect disease vectors
}

\author{
Felipe de Mello Vigoder ${ }^{1,2} /{ }^{+}$, Michael Gordon Ritchie ${ }^{2}$, \\ Gabriella Gibson ${ }^{3}$, Alexandre Afranio Peixoto ${ }^{1,4+}$
}

'Laboratório de Biologia Molecular de Insetos, Instituto Oswaldo Cruz-Fiocruz, Rio de Janeiro, RJ, Brasil ${ }^{2}$ Centre for Biological Diversity, School of Biology, University of St Andrews, Fife, Scotland, UK ${ }^{3}$ Natural Resources Institute, University of Greenwich,

Medway Campus, Chatham Maritime, Kent, UK ${ }^{4}$ Instituto Nacional de Ciência e Tecnologia em Entomologia Molecular, Brasil

Acoustic signalling has been extensively studied in insect species, which has led to a better understanding of sexual communication, sexual selection and modes of speciation. The significance of acoustic signals for a blood-sucking insect was first reported in the XIX century by Christopher Johnston, studying the hearing organs of mosquitoes, but has received relatively little attention in other disease vectors until recently. Acoustic signals are often associated with mating behaviour and sexual selection and changes in signalling can lead to rapid evolutionary divergence and may ultimately contribute to the process of speciation. Songs can also have implications for the success of novel methods of disease control such as determining the mating competitiveness of modified insects used for mass-release control programs. Species-specific sound "signatures" may help identify incipient species within species complexes that may be of epidemiological significance, e.g. of higher vectorial capacity, thereby enabling the application of more focussed control measures to optimise the reduction of pathogen transmission. Although the study of acoustic communication in insect vectors has been relatively limited, this review of research demonstrates their value as models for understanding both the functional and evolutionary significance of acoustic communication in insects.

Key words: sandflies - mosquitoes - triatomines - tsetse

Insects communicate through several modalities including sound. One of them is through acoustic signals (Ewing 1989, Drosopoulos \& Claridge 2005). Acoustic signals may be produced in a variety of ways, the most common being wing vibration (e.g. Drosophila) and stridulation of different body structures (e.g. Orthoptera). Acoustic signals are received by a variety of sensory structures; for example, in many Diptera, the antennae and Johnston's organs (JO) at their base perceive sounds created by the wing vibrations of other insects flying nearby (Göpfert et al. 1999, Gibson et al. 2010), whereas highly elaborate tympanal ears (not unlike mammal ears in some design features) have evolved in Orthoptera (Montealegre et al. 2012) and Diptera (Robert et al. 1999).

Acoustic signals are usually associated with sexual behaviour and are frequently used by many insects during courtship or male-male competition (Ewing 1989, Drosopoulos \& Claridge 2005) although they can also be used as a defence mechanism to deter predators (Masters 1979). The precise function and design of songs can also depend on whether they are used as a long-range signal to attract potential mates or at close-range where they can be more stimulatory (Ewing 1989, Tauber \& Eberl 2003, Mendelson \& Shaw 2006). When associated with mating behaviour songs are frequently under sexual selection and in theory signal-preference co-evolution can

\footnotetext{
doi: 10.1590/0074-0276130390

$\dagger$ In memoriam

+ Corresponding author: fvigoder@gmail.com

Received 1 August 2013

Accepted 30 October 2013
}

lead to rapid evolution, (Lande 1981). Evidence from comparative studies (Gleason \& Ritchie 1998, Ritchie 2007) supports the idea that songs can diverge particularly quickly. As such, acoustic signals have been used extensively in evolutionary studies, both because they can provide species-specific traits for taxonomic studies, but also because interspecific song differences are often involved in pre-mating reproductive isolation, one of the main causes of restricted gene-flow between closely related species (Gleason 2005).

Over 250 million people per year are infected with vector-borne pathogens around the world, leading to over one million deaths annually (World Health Organization, available from who.int). A greater understanding of the sensory-controlled behaviour of vector species can aid the design of improved surveillance and population control methods (malERA 2011) and contribute to our general knowledge of the evolution of animal behaviour.

Acoustic behaviour has been reported in only four of the major groups of haematophagous (blood-sucking) insects. There is evidence that sound plays an important role in mating behaviour for mosquitoes and sandflies and less clear-cut evidence for this in triatomine bugs and the tsetse fly. The discovery of species-specific courtship songs in sandfly species opened up new approaches to the investigation of behavioural phenotypes that play a role in gene flow and species isolation (de Souza et al. 2004, Araki et al. 2009). Gibson and Russell (2006) described an entirely novel form of auditory interaction in mosquitoes, involving a mechanism of continuous feedback between two flying mosquitoes that leads to complex interactions between harmonics of their wing-beat frequencies. Since then, "duets" have been described in several vector mosquito species (Cator et al. 2009, 2010, Warren et al. 2009, Gibson et al. 2010, 
Pennetier et al. 2010, Cator \& Harrington 2011). These recent developments have catalysed interest in bloodsucking insects as models for functional and evolutionary bio-acoustic studies. Here we review the most salient studies of acoustic signalling in insect disease vectors and discuss potential new research directions for this relatively unexplored field.

Mosquitoes (Diptera: Culicidae) - An elegant study of mosquito physiology by Christopher Johnston (1855) was the first to describe the specialised hearing organ at the base of the antennae in dipterans that bears his name, the JO. The hearing apparatus of mosquitoes is structured much like an inverted umbrella, with the antenna held centrally in the JO by its ring of 60-80 "prongs" (scolopidia) that are thought to mechanically detect antennal vibrations, thereby stimulating thousands of sensory cells lining the $\mathrm{JO}$, which carry the signal to the central nervous system (Fig. 1A). Mosquitoes have the most acute sense of hearing known amongst invertebrates (Göpfert \& Robert 2000) and Johnston himself speculated that audition was associated with mating behaviour.

Mosquitoes transmit a wide range of pathogens that are the causative agents of debilitating and life-threatening diseases, such as malaria, dengue fever and yellow fever, making them the most epidemiologically important insect group. Although hearing might have a role in host finding, as for example in the case of the frog-biting mosquito Uranotaenia lowii, whose females are attracted by male frog song (Borkent \& Belton 2006), acoustic signals mainly play a particularly important role in mosquito mating behaviour.
Mosquito sounds are produced by the beating of their wings during flight. Males and females usually have quite different wing-beat frequencies, with males generally producing higher frequencies due to their smaller size (Belton 1994, Clements 1999). The sound frequencies of several species, particularly of the Anopheles, Culex and Aedes genera, have been analysed (Clements 1999). Their wing-beat frequencies vary between $200-$ $800 \mathrm{~Hz}$ and produce multiple harmonics, the lowest of which are defined as the "fundamental" frequency or "first harmonic" and is equivalent to the number of times a mosquito beats its wings per second. Higher harmonics are simply multiples of the first harmonic and can extend up into the 1,000's of $\mathrm{Hz}$.

For many years, it was thought that acoustic communication in mosquitoes involved only a one-way flow of information, with females sending the signal and males receiving it. The basis for this conclusion was the observation that males of many species respond to female flight tones by flying towards the source of sound (Charlwood \& Jones 1979, Duhrkopf \& Hartberg 1992, Belton 1994, Clements 1999) and males have more "plumose" antennae (i.e., many more fibrillae or "hairs" on each antenna), creating a greater surface area with which to detect sound (Belton 1994, Clements 1999). Gibson and Russell (2006) were the first to show, using Toxorhynchites brevipalpis mosquitoes, that females also respond to male flight tones, albeit not by altering their flight course. Both sexes responded to a pure tone stimulus (i.e., only a fundamental frequency, with no higher harmonics) within a range of frequencies close to their
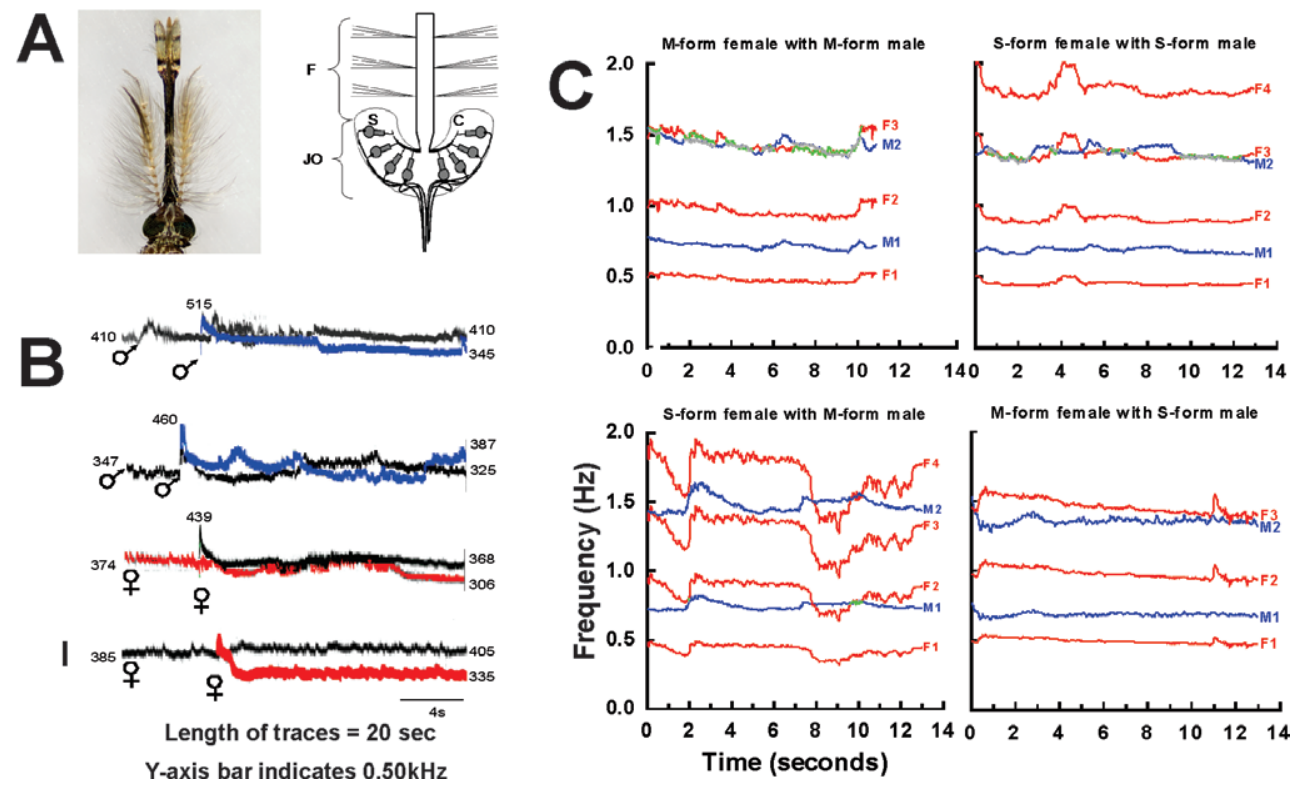

Fig. 1: mosquito acoustic communication. A: photograph of the head of an Anopheles gambiae s.s. male and a schematic diagram showing a cross-section of the antenna with hair-like fibrillae (F), the Johnston's organ (JO) at the base of the antenna and the ring of mechanosensory scolopidia (S) and associated sensory cells (SC) (Belton 1989) [modified from Warren et al. (2009) with permission of the publisher]; B: spectrograms of the fundamental components of the flight tones of the mosquito Toxorhynchites brevipalpis for opposite and same-sex pairs (male $\widehat{\partial}$, blue; female $\$$, red) [modified from Gibson and Russell (2006) with permission of the publisher]; C: spectrograms of the flight tones of male-female pairs of the M and S molecular forms of An. gambiae s.s., showing the harmonics of males (blue) and females (red) and periods of frequency convergence (gray male, green female) [from Pennetier et al. (2010) with permission of the publisher]. 
own flight tone by altering their wing-beat frequency until they nearly synchronised with the pure tone (Fig. 1B). Similarly, both sexes responded to the sound of a nearby flying mosquito of the opposite sex by altering their respective wing-beat frequencies until they were nearly synchronised with each other. If both mosquitoes were of the same sex, however, they actively avoided synchronising. Thus, they concluded that mosquitoes could use this mode of auditory communication as a mechanism of sex recognition.

Since then, acoustic duetting has been observed in the disease vectors Aedes aegypti, Culex quinquefasciatus and Anopheles gambiae s.s. [Cator et al. (2009, 2010), Warren et al. (2009), Pennetier et al. (2010), respectively], but involves a rather more complex interaction than found in T. brevipalpis. In these vector species, the basic wing-beat frequencies of males and females are significantly different and, therefore, they cannot synchronise at their respective first harmonics (i.e., fundamental frequencies). Instead, they move toward synchronisation at a higher harmonic, converging on a frequency that is common to both mosquitoes. For example, if a female is flying at a fundamental frequency of $480 \mathrm{~Hz}$, her third harmonic would be $1,440 \mathrm{~Hz}$ and a male flying at $710 \mathrm{~Hz}$ would produce a second harmonic at $1,420 \mathrm{~Hz}$, so there would be only $20 \mathrm{~Hz}$ difference between these higher harmonics. Both mosquitoes would adjust their respective wing-beat frequencies to converge on a frequency in the region of $1,430 \mathrm{~Hz}$ (Fig. 1C).

Although there is little doubt that "frequency convergence" occurs, the details as to how this highly unusual mechanism of duetting is accomplished at the biophysiological level have not yet been fully elucidated. As for the functional significance of frequency convergence, some data suggest that it might be under sexual selection and that the male wing-beat frequency could function as an "honest" signal of male quality (Cator et al. 2010, Cator \& Harrington 2011), potentially providing females with some indirect benefits, such as "sexier" sons. There is evidence that the ability to converge frequency is heritable (Cator \& Harrington 2011).

The frequency convergence of flight tones may also have an important role in species-specific recognition of potential mating partners. It was observed in tethered mosquitoes of the closely related " $\mathrm{M}$ " and " $\mathrm{S}$ " molecular forms of An. gambiae s.s. that frequency convergence occurred most often when the male and female were both of the same molecular form (Pennetier et al. 2010). These two forms represent cryptic species (Lehmann \& Diabaté 2008, Diabaté et al. 2009, Lee et al. 2009, Simard et al. 2009, Lawniczak et al. 2010), with the M form recently officially named Anopheles coluzzii Coetzee \& Wilkerson and the $\mathrm{S}$ form retaining the name An. gambiae s.S. (Coetzee et al. 2013). Across most of their sympatric distribution they exhibit reproductive isolation and even though the mechanisms that cause this isolation are not fully understood (Sawadogo et al. 2013), it seems that auditory interactions may contribute to sexual isolation between the forms, even though the wing-beat frequency ranges of the two forms overlap (Tripet et al. 2004, Diabaté et al. 2009, Pennetier et al. 2010).
The consistent evidence for duetting observed in mosquitoes from different genera suggests that this phenomenon may be quite common in Culicidae. Also, a review of the available data for a number of mosquito species from the Aedes, Anopheles and Culex genera suggests that frequency convergence between the sexes may always occur at the third female and second male harmonic (FM Vigoder, AA Peixoto, unpublished observations).

Sandflies (Diptera: Psychodidae: Phlebotominae) - Lutzomyia longipalpis, the main vector of visceral leishmaniasis in the Americas, constitutes a complex of cryptic species (Ward et al. 1988, Lanzaro et al. 1993). For some time it was not clear whether the Brazilian populations of this vector represented one species or several sibling species [reviewed by Bauzer et al. (2007) and Maingon et al. (2008)]. Among the best pieces of evidence that there are more than one species in Brazil are the distinctive "songs" produced by males from different populations (de Souza et al. 2002, Souza et al. 2004, Araki et al. 2009). These songs are produced by wing vibrations, as in Drosophila, but are unusual in that they are produced during copulation rather than during pre-copulatory courtship. The copulatory courtship songs of Lu. longipalpis s.l. are likely to be involved in reproductive isolation since mating experiments show a high level of insemination failure in copulations between sibling species that produce different songs (Ward et al. 1988, Souza et al. 2008). Why female choice should be based on copulatory courtship is not well understood, but it may suggest that cryptic female choice (Eberhard 1996) possibly related to sperm competition (Hoikkala $\&$ Crossley 2000), is important during mating in this insect vector.

Two different songs are produced by males during copulation and have been called primary and secondary songs (Souza et al. 2004, Araki et al. 2009). The primary song is produced during every mating and shows differences among Brazilian populations of Lu. longipalpis

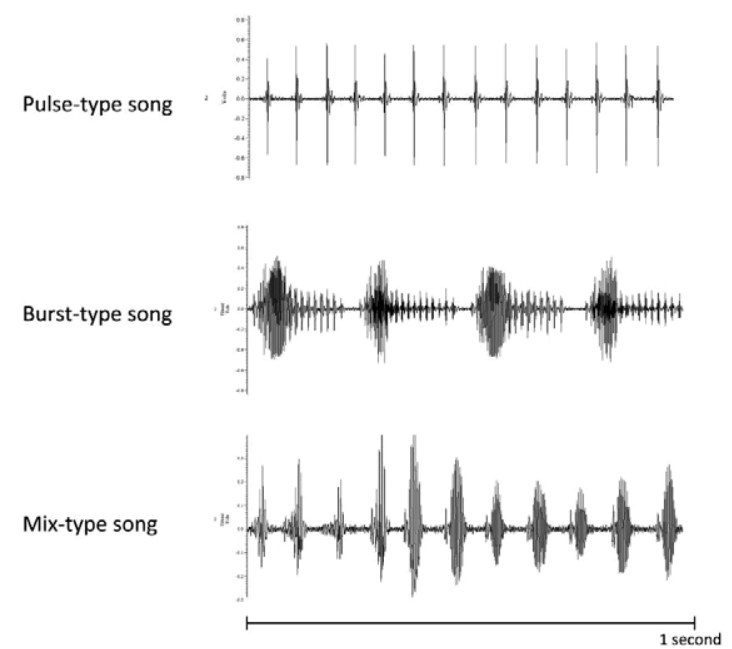

Fig. 2: sample of the three types of songs found in the sandfly Lutzomyia longipalpis. The mix-type starts with a pattern similar to a pulse-type and then switches to a more burst-type like song. Recordings show 1 sec of song. 
s.l. (including some pairs of sympatric species), while the secondary song is not always produced and seems to be somewhat similar in all populations, although it has not been extensively studied (Souza et al. 2004, Araki et al. 2009).

Three main types of primary song have been found in populations of the $\mathrm{Lu}$. longipalpis complex so far: pulsetype, burst-type and mix-type (Souza et al. 2004, Araki et al. 2009). The pulse-type song, characterised by short pulses (Fig. 2), is the most variable of the three types and five distinct patterns have been found among populations in Brazil, with differences in many song parameters, suggesting that each pattern belongs to a different cryptic species. This finding is consistent with molecular data, which shows that pulse-type populations have higher genetic differentiation among them than burst-type populations (Souza et al. 2004, Araki et al. 2009).

The main characteristic of the burst-type song is that it has polycyclic long pulses that are highly modulated in amplitude and frequency (Fig. 2). This song type was found in a number of populations of the Lu. longipalpis complex in Brazil. However, all of the populations produced the same pattern and similar song parameter values, suggesting that they constitute a single species, a finding that is consistent with the molecular data (Souza et al. 2004, Araki et al. 2009). Interestingly, in at least three localities where pairs of sibling species occur in sympatry, they differ in song type, with one producing the pulse-type song and the other producing the bursttype song. This reinforces the idea that this acoustic signal contributes to sexual isolation by species recognition (Souza et al. 2004, Araki et al. 2009).

The mix-type song has been described in only one population (Araki et al. 2009). It starts with a segment that resembles pulse-type song and then switches to a segment that is more similar to the burst-type song (Fig. 2). However, both segments are clearly distinct from the pulse-type and burst-type songs, showing significant differences in both pattern and parameter values (Araki et al. 2009) (Fig. 2).

Acoustic communication has also been observed in other sandfly species. Males of Lutzomyia cruzi and Lutzomyia migonei also sing during copulation (Vigoder et al. 2010a, b), while Lutzomyia intermedia produces a pre-copulation courtship song (Vigoder et al. 2011). Lu. cruzi is close related to Lu. longipalpis s.l. and they produce a burst-type primary song similar to the one observed in populations of this species complex (see above), but with significant differences in song parameters (Vigoder et al. 2010a). Male copulation song in Lu. migonei is composed of short trains of pulse song different from the ones observed in Lu. longipalpis s.l. (Vigoder et al. 2010b). In Lu. intermedia only pre-copulation songs were observed and males produce a pulse song that is different from those of the other species (Vigoder et al. 2011). The three Brazilian populations of this vector so far recorded have similar song parameters. Since no copulation was observed in the experiments, it is not yet clear if they also sing during copulation as in the other sandfly species, but it remains a possibility (Vigoder et al. 2011). Pre-copulation acoustic signals produced by both sexes have also been observed in Lu. longipalpis s.l.
(Ward et al. 1988), but their function is less clear as some of these sounds are also observed when the sexes are isolated in single-sex groups (FM Vigoder, AA Peixoto, unpublished observations).

Acoustic communication is probably widespread in Phlebotominae, but further studies, especially playback experiments (Ritchie et al. 1998), are necessary to assess in more detail the role of male songs in sandfly sexual behaviour. Recently, Li et al. (2012) showed that playback of copulatory song in Drosophila can greatly extend copulation duration, which may cause greater reproductive success if it leads to higher levels of insemination.

Triatomines (Hemiptera: Reduviidae) - Triatomine bugs are vectors of trypanosomes, including the causative agent of Chagas disease in the Americas. Some species of this group are able to produce sounds by stridulation (Schofield 1977, Lazzari et al. 2006). Triatomine bugs stridulate by rubbing the tip of the proboscis in the stridulatory organ of the prosternum (Schofield 1977, Di Luciano 1981). The stridulatory organ constitutes a series of longitudinal grooves in the cuticle and is similar in all species of this subfamily (Schofield 1977, Di Luciano 1981). In Triatoma infestans, this organ is present in both nymph and adult forms and does not present sexual dimorphism. In first instar nymphs, it is underdeveloped, but by the second instar, this organ is already fully formed and the stripes become parallel bars. As the insect metamorphoses from one instar to the next, the stridulatory organ increases in length and width, but the number of stripes does not change (Di Luciano 1981). Only the central region, about $1 / 3$ of the organ, is stroked during stridulation (Roces \& Manrique 1996). While some bugs may stridulate by doing only a downward movement, as in Dipetalogaster maximus, others do both downward and upward movements (e.g. T. infestans and Rhodnius prolixus) (Schofield 1977, Roces \& Manrique 1996, Manrique \& Schilman 2000).

Even though these bugs are able to perceive sound with the JO (Schofield 1977), it is not clear if the sound itself has an actual role in intra-specific communication since no behavioural responses have been observed in playback experiments (Schofield 1977, Lazzari et al. 2006). Some authors have suggested that the role of stridulation in triatomines may be through a substrateborne vibration transmitted either via the ground or via the body itself (Manrique \& Lazzari 1994, Manrique \& Schilman 2000, Lazzari et al. 2006). Either way, stridulation produces a vibrational signal that seems to be involved in triatomine communication.

The first vibrational signal described in triatomines was a disturbance stridulation produced when the bugs were immobilised or handled (Moore 1961, Schofield 1977, Roces \& Manrique 1996, Manrique \& Schilman 2000). In spite of some differences, this stridulation has important similarities in all species analysed so far in different genera, such as, Triatoma, Rhodnius, Dipetalogaster and Panstrongylus (Schofield 1977, Schilman et al. 2001). Although stridulation produces a wide range of frequencies including ultrasound, the temporal patterns are generally the same in all cases (Schofield 1977, Schilman et al. 2001). 
It has been suggested that this stridulation is used as a defence mechanism against predators (Leston 1957, Schofield 1977), as in some other stridulating insects (Masters 1979, 1980). Indeed, this is probably the evolutionary origin of most "singing" structures in insects (Ewing 1989). The fact that many bug species produce a similar stridulation pattern reinforces the defence theory since these sounds could act as a Mullerian convergent mimetic signal, helping to "train" predators to avoid attacking them (Masters 1980, Schilman et al. 2001). Some studies have shown that disturbance stridulation can deter some predators (Masters 1979, 1980). This suggests that in this case stridulation is used for interspecific communication (Manrique \& Schilman 2000), especially considering that it does not incite behavioural modification in Panstrongylus megistus during playback experiments (Schofield 1977). Recently, vibrational communication in bugs has been shown to be remarkably complex; mother treehoppers were shown to signal their offspring, training them to avoid unnecessary false alarm signals in response to non-predators (Hamel \& Cocroft 2012).

Female bugs can stridulate to reject copulation after the male mounts her. Female stridulation makes the male stop moving or dismount and leave (Manrique \& Lazzari 1994, Manrique \& Schilman 2000, Pires et al. 2004). This behaviour was recorded as a substrate-borne signal (Manrique \& Lazzari 1994, Manrique \& Schilman 2000). T. infestans and $R$. prolixus show different maledeterring stridulations, with the former having a lower repetition rate (23.8 syllables/s) and frequency (700-800 $\mathrm{Hz}$ ) than the latter (35.6 syllables/s and 1,500 Hz, respectively). In both species, this type of stridulation is faster than the disturbance type (Manrique \& Lazzari 1994, Manrique \& Schilman 2000).

The likely receptor of the substrate-borne signal is the distal scoloparia of the tibia [Autrum \& Schneider (1948), cited by Manrique \& Schilman (2000)]. However, the intensity and the frequency of the vibratory signals produced by $R$. prolixus do not fall within the threshold of sensitivity range of this organ [Autrum \& Schneider (1948), cited by Manrique \& Schilman (2000)]. Since males do change their behaviour in response to the signal (they stop courtship), even when females are artificially vibrated (Lazzari et al. 2006), a potential explanation is that there is another yet unknown receptor for substrateborne vibration.

Tsetse (Diptera: Glossinidae) - The tsetse fly, Glossina spp, is the vector of trypanosomes that are the causative agent of sleeping sickness in humans and nagana in cattle in Africa. The name "tsetse" is in fact an onomatopoeic word for the characteristic buzzing the flies make (Saini 1984). Many different sounds are produced by tsetse in various contexts that have been described as singing, buzzing, squeaking or pinging (Saini 1984). During sound production, flies vibrate their wings, but the sound is actually produced by the axillary wing sclerites of the wing junction since removing the wings does not prevent sound production (Popham et al. 1978). These songs are associated with several behaviours, including mating and blood-feeding. In Glossina morsitans morsitans sound production is more intense in the morning, with a peak in the first couple of hours (Saini 1981a), although it not under the control of a circadian rhythm because the pattern of timing is not maintained in constant darkness (Saini 1981a).

One of the many sounds produced by tsetse flies is associated with feeding and can be produced before and after blood intake (Popham et al. 1978, Saini 1981a, b, 1983). The pre-feeding buzz has a short duration $(\sim 0.25$ sec) and occurs most often in mated females (Popham et al. 1978, Saini 1983). Post-feeding songs are more common generally and once again occur most frequently in mated females (Popham et al. 1978, Saini 1983). They can be produced up to $30 \mathrm{~min}$ after a blood meal, even if the host is removed (Popham et al. 1978, Saini 1983). Post-feeding sounds have been described for G. m. morsitans, Glossina morsitans orientalis, Glossina palpalis, Glossina austeni, Glossina tachinoides and Glossina brevipalpis and show distinct species-specific patterns (Saini 1984). The sound is received by the antennal flagellum and induces unfed flies to become mobile and unsheathe their proboscis, but only when species-specific song is heard (Popham et al. 1978, Saini 1984). This suggests that this type of song is involved in attracting other individuals of the same species to a suitable feeding place on an animal (Popham et al. 1978). This can be important since flies cannot feed in areas where the fur is excessive (Popham et al. 1978). Although at first hand the idea of attracting other individuals to a feeding site might sound counter-intuitive since there is the suggestion of group selection, individual benefits of cooperative blood-feeding have been demonstrated in sandflies (Tripet et al. 2009).

Howe and Lehane (1986) observed that the muscle contraction involved in generating sound also produces heat, which increases the thoracic temperature. They found that the duration of sound production by the fly after feeding was related to the initial thoracic temperature, which suggests this humming is important for endothermic control. In this way, it is possible that sound production is a by-product of thermal control, to optimise flight "take-off" that would otherwise be more difficult with the excessive weight of a full blood meal. The honey bee, among other insects, is also known to increase its temperature prior to take-off by producing a buzzing sound (Seeley \& Tautz 2001).

Tsetse males also "sing" to females during courtship. In some species, such as Glossina fuscipes fuscipes, males start to sing prior to mounting and continue after copulation starts and at regular intervals until the ejaculatory phase starts, i.e., the final phase when the seminal fluid is transferred (Rudrauf 1977). In others species, such as G. m. morsitans, males produce sound only after mating has begun, hence displaying only copulatory song (Saini 1985). This species sings sporadically during the first $5 \mathrm{~min}$ and after that only when the female becomes agitated or if the couple is disturbed (Saini 1985). After the first copulation, both male and female can produce acoustic signals that leads to a second copulation, but if the female is not receptive it makes a different sound, rejecting the male (Saini 1985). 
Females of G. m. morsitans also produce a sound after parturition. This song is longer than the others described above, lasting for approximately $6 \mathrm{~min}$ instead of seconds (Denlinger et al. 1983), but its function is not clear.

Despite the known importance of the antennal flagellum for detecting post-feeding sound (Popham et al. 1978), more recently it has been found that the prothorax membrane could possibly be a tympanal hearing organ (Tuck et al. 2009). Interestingly, these two types of receptors usually have different properties, with tympani having greater sensitivity to long-range sounds and higher frequencies (Yack 2004). Considering the wide variety of sounds produced by tsetse flies, these different receptors could be involved in several distinct contexts.

Perspectives - The mechanisms and functions of sound production and detection in insects have been investigated across the disciplines from behaviour to neurobiology and increased our understanding of sexual communication, sexual selection and modes of speciation. In the case of insect disease vectors, acoustic communication studies may also provide practical benefits. Understanding song variation can allow the identification of cryptic siblings in species complexes (Araki et al. 2009). Knowledge of acoustic communication can contribute to vector control with sound traps to monitor or control males of vector mosquito species (Belton 1994). Despite some technological difficulties, recent tests have proven successful in increasing Aedes polynesiensis male capture in the field using sound traps (Stone et al. 2013). The success of vector control strategies based on the release of sterile or genetically modified males depends on the mating competitiveness of released males in relation to wild males, which may involve speciesspecific acoustic behaviour. Condition-dependence of sexual signals may lead to greater sensitivity of songs to male condition. A related important question not yet addressed is the influence of parasite infection on sound production and the consequences for sexual fitness. This could have important epidemiological implications, as it likely affects the dynamics of disease transmission and mating success.

There are many possible directions for future research on acoustic behaviour. For example, the function(s) of many of the sounds that have been described in a number of species are poorly understood, especially in tsetse flies and triatomine bugs. If song variation can be demonstrated to influence reproductive isolation between species, then understanding song pattern variation will allow us to more accurately predict the spread of insecticide resistance because gene flow will reflect song pattern variation. However, the extent to which behaviourally induced reproductive isolation can impede the flow of advantageous genes between hybridising species is likely to be a complex interaction between the strength of selection and the effectiveness of "barrier loci" (such as song and preference genes) in countering gene flow (Abbott et al. 2013). This could also be important in relation to decisions concerning where the application of particular insecticides may need to be controlled more carefully. Songs may also prove to be valuable phenotypes to study host-parasite interactions since it is well- known that parasites can affect host behaviour (Adamo 2013). This aspect can be particularly important in tsetse where both sexes can become infected, especially considering that constant infection pressure can lead to co-evolution between host and parasite and possibly cospeciation (Miller et al. 2010).

The genetic basis of sound production and reception is also an area still unexplored in insect disease vectors. As a number of genetic and molecular tools derived from those developed for model species such as Drosophila melanogaster become available for blood-sucking disease vectors (Sant'Anna et al. 2008, Kokoza \& Raikhel 2011), some of the neurogenetic bases of sound production and hearing might be unravelled in these medically important insects as is currently under way in Drosophila (Murthy 2010, von Philipsborn et al. 2011). Mutants of the sex determining pathway of D. melanogaster are available which disturb male-specific behaviours, including the ability to sing and mate successfully (Ryner et al. 1996) and some of these seem to have conserved roles throughout the Diptera (Meier et al. 2013). Integrative studies of song variation and population genetics will allow detailed inference of species boundaries in species complexes such as Anopheles and the contribution of trait variation to patterns of speciation and genomic differentiation in these important disease vectors.

\section{ACKNOWLEDGEMENTS}

We dedicate this review in memory of Alexandre Afranio Peixoto.

\section{REFERENCES}

Abbott R, Albach D, Ansell S, Arntzen JW, Baird SJE, Bierne N, Boughman J, Brelsford A, Buerkle CA, Buggs R, Butlin RK, Dieckmann U, Eroukhmanoff F, Grill A, Cahan SH, Hermansen JS, Hewitt G, Hudson AG, Jiggins C, Jones J, Keller B, Marczewski T, Mallet J, Martinez-Rodriguez P, Most M, Mullen S, Nichols R, Nolte AW, Parisod C, Pfennig K, Rice AM, Ritchie MG, Seifert B, Smadja CM, Stelkens R, Szymura JM, Vainola R, Wolf JBW, Zinner D 2013. Hybridization and speciation. J Evol Biol 26: 229-246.

Adamo SA 2013. Parasites: evolution's neurobiologists. J Exp Biol 216: 3-10.

Araki AS, Vigoder FM, Bauzer LGSR, Ferreira GEM, Souza NA, Araújo IB, Hamilton JG, Brazil RP, Peixoto AA 2009. Molecular and behavioral differentiation among Brazilian populations of Lutzomyia longipalpis (Diptera: Psychodidae: Phlebotominae). Plos Negl Trop Dis 3: e365.

Bauzer LGSR, Souza NA, Maingon RDC, Peixoto AA 2007. Lutzomyia longipalpis in Brazil: a complex or a single species? A minireview. Mem Inst Oswaldo Cruz 102: 1-12.

Belton P 1989. The structure and probable function of the internal cuticular parts of Johnston's organ in mosquitoes (Aedes aegypti). Can J Zool 67: 2625-2632.

Belton P 1994. Attraction of male mosquitos to sound. J Am Mosq Control Assoc 10: 297-301.

Borkent A, Belton P 2006. Attraction of female Uranotaenia lowii (Diptera:Culicidae) to frog calls in Costa Rica. Can Entomol 138: 91-94.

Cator LJ, Arthur BJ, Harrington LC, Hoy RR 2009. Harmonic convergence in the love songs of the dengue vector mosquito. Science 323: $1077-1079$. 
Cator LJ, Harrington LC 2011. The harmonic convergence of fathers predicts the mating success of sons in Aedes aegypti. Anim Behav 82: 627-633.

Cator, LJ, Ng'Habi KR, Hoy RR, Harrington LC 2010. Sizing up a mate: variation in production and response to acoustic signals in Anopheles gambiae. Behav Ecol 21: 1033-1039.

Charlwood JD, Jones MDR 1979. Mating behaviour in the mosquito Anopheles gambiae s.l. I. Close range and contact behaviour. Physiol Entomol 4: 111-120.

Clements AN 1999. The biology of mosquitoes: sensory, reception and behaviour, Vol. 2, CABI Publishing, UK, 752 pp.

Coetzee M, Hunt RH, Wilkerson R, Della Torre A, Coulibaly MB, Besansky NJ 2013. Anopheles coluzzii and Anopheles amharicus, new members of the Anopheles gambiae complex. Zootaxa 3619: 246-274.

de Souza NA, Vigoder FM, Araki AS, Ward RD, Kyriacou CP, Peixoto AA 2004. Analysis of the copulatory courtship songs of Lutzomyia longipalpis in six populations from Brazil. J Med Entomol 41: 906-913.

de Souza NA, Ward RD, Hamilton JG, Kyriacou CP, Peixoto AA 2002. Copulation songs in three siblings of Lutzomyia longipalpis (Diptera: Psychodidae). Trans R Soc Trop Med Hyg 96: 102-103.

Denlinger DL, Saini RK, Chaudhury MFB 1983. Parturition in the tsetse fly Glossina morsitans - pattern of activity, sound production and evidence for control by the mothers brain. $J$ Insect Physiol 29: 715-717.

Di Luciano VS 1981. Morphology of the stridulatory groove of Triatoma infestans (Hemiptera, Reduviidae). J Med Entomol 18: 24-32.

Diabaté A, Dao A, Yaro AS, Adamou A, Gonzalez R, Manoukis NC, Traoré SF, Gwadz RW, Lehmann T 2009. Spatial swarm segregation and reproductive isolation between the molecular forms of Anopheles gambiae. Proc R Soc Lond B Biol Sci 276: 4215-4222.

Drosopoulos S, Claridge M 2005. Insect sounds and communication: physiology, behaviour, ecology and evolution (contemporary topics in entomology), CRC press, Boca Raton, $552 \mathrm{pp}$.

Duhrkopf RE, Hartberg WK 1992. Differences in male mating response and female flight sounds in Aedes aegypti and Ae. albopictus (Diptera, Culicidae). J Med Entomol 29: 796-801.

Eberhard W 1996. Female control: sexual selection by cryptic female choice, Princeton University Press, Princeton, 472 pp.

Ewing AW 1989. Arthropod bioacoustics, Cornell University Press, New York, 26 pp.

Gibson G, Russell IJ 2006. Flying in tune: sexual recognition in mosquitoes. Curr Biol 16: 1311-1316.

Gibson G, Warren B, Russell IJ 2010. Humming in tune: sex and species recognition by mosquitoes on the wing. Jaro-J Assoc Res Oto 11: 527-540

Gleason JM 2005. Mutations and natural genetic variation in the courtship song of Drosophila. Behav Genet 35: 265-277.

Gleason JM, Ritchie MG 1998. Evolution of courtship song and reproductive isolation in the Drosophila willistoni species complex: do sexual signals diverge the most quickly? Evolution 52: 1493-1500.

Göpfert MC, Bridgel H, Robert D 1999. Mosquito hearing: soundinduced antennal vibrations in male and female Aedes aegypti. J Exp Biol 202: 2727-2738.

Göpfert MC, Robert D 2000. Nanometre-range acoustic sensitivity in male and female mosquitoes. Proc R Soc Lond B Biol Sci 267: 453-457.

Hamel JA, Cocroft RB 2012. Negative feedback from maternal signals reduces false alarms by collectively signalling offspring. Proc R Soc Lond B Biol Sci 279: 3820-3826.
Hoikkala A, Crossley S 2000. Copulatory courtship in Drosophila: behavior and songs of D. birchii and D. serrata. J Insect Behav 13: 71-86.

Howe MA, Lehane MJ 1986. Post-feed buzzing in the tsetse, Glossina morsitans morsitans, is an endothermic mechanism. Physiol Entomol 11: 279-286.

Johnston C 1855. Auditory apparatus of the Culex mosquito. Quarterly Journal of Microscopical Science 3 (Old Series): 97-102.

Kokoza VA, Raikhel AS 2011. Targeted gene expression in the transgenic Aedes aegypti using the binary Gal4-UAS system. Insect Biochem Mol Biol 41: 637-644.

Lande R 1981. Models of speciation by sexual selection on polygenic traits. Proc Natl Acad Sci USA 78: 3721-3725.

Lanzaro GC, Ostrovska K, Herrero MV, Lawyer PG, Warburg A 1993. Lutzomyia longipalpis is a species complex: genetic divergence and interspecific hybrid sterility among three populations. Am J Trop Med Hyg 48: 839-847.

Lawniczak MK, Emrich SJ, Holloway AK, Regier AP, Olson M, White B, Redmond S, Fulton L, Appelbaum E, Godfrey J, Farmer C, Chinwalla A, Yang SP, Minx P, Nelson J, Kyung K, Walenz BP, Garcia-Hernandez E, Aguiar M, Viswanathan LD, Rogers YH, Strausberg RL, Saski CA, Lawson D, Collins FH, Kafatos FC, Christophides GK, Clifton SW, Kirkness EF, Besansky NJ 2010. Widespread divergence between incipient Anopheles gambiae species revealed by whole genome sequences. Science 330: 512-514.

Lazzari CR, Manrique G, Schilman P 2006. Vibrational communication in Triatominae (Heteroptera: Reduviidae). In S Drosopoulos, M Claridge, (eds.), Insect sounds and communication. Physiology, behaviour, ecology and evolution, CRC Press, Boca Raton, 297-304.

Lee Y, Cornel AJ, Meneses CR, Fofana A, Andrianarivo AG, McAbee RD, Fondjo E, Traoré SF, Lanzaro GC 2009. Ecological and genetic relationships of the Forest-M form among chromosomal and molecular forms of the malaria vector Anopheles gambiae sensu stricto. Malar J 8: 75.

Lehmann T, Diabaté A 2008. The molecular forms of Anopheles gambiae: A phenotypic perspective. Infect Genet Evol 8: 737-746.

Leston D 1957. The stridulatory mechanisms in terrestrial bugs. Proc $R$ Soc Lond B Biol Sci 128: 369-386.

Li YF, Wen SY, Ritchie MG 2012. Copulatory song in three species of the Drosophila montium subgroup extends copulation and shows unusual genetic control. Anim Behav 83: 233-238.

Maingon RD, Ward RD, Hamilton JG, Bauzer LG, Peixoto AA 2008. The Lutzomyia longipalpis species complex: does population sub-structure matter to Leishmania transmission? Trends Parasitol 24: 12-17.

malERA - Consultative Group on Vector Control 2011. A research agenda for malaria eradication: vector control. PLoS Med 8: e1000401.

Manrique G, Lazzari CR 1994. Sexual behavior and stridulation during mating in Triatoma infestans (Hemiptera: Reduviidae). Mem Inst Oswaldo Cruz 89: 629-633.

Manrique G, Schilman PE 2000. Two different vibratory signals in Rhodnius prolixus (Hemiptera : Reduviidae). Acta Trop 77: 271-278

Masters WM 1979. Insect disturbance stridulation - Its defensive role. Behav Ecol Sociobiol 5: 187-200.

Masters WM 1980. Insect disturbance stridulation - Characterization of airborne and vibrational components of the sound. J Comp Physiol [A] 135: 259-268.

Meier N, Käppeli SC, Hediger Niessen M, Billeter JC, Goodwin SF Bopp D 2013. Genetic control of courtship behavior in the house- 
fly: evidence for a conserved bifurcation of the sex-determining pathway. PLoS ONE 8: e62476.

Mendelson TC, Shaw KL 2006. Close-range acoustic signaling and mate choice in Hawaiian crickets (Gryllidae : Laupala). Behav Ecol Sociobiol 59: 770-776.

Miller WJ, Ehrman L, Schneider D 2010. Infectious speciation revisited: impact of symbiont-depletion on female fitness and mating behavior of Drosophila paulistorum. PLoS Pathog 6: e1001214.

Montealegre-Z F, Jonsson T, Robson-Brown KA, Postles M, Robert D 2012. Convergent evolution between insect and mammalian audition. Science 338: 968-971.

Moore TE 1961. Audiospectrographic analysis of sounds of Hemiptera and Homoptera. Ann Entomol Soc Am 54: 273-291.

Murthy M 2010. Unravelling the auditory system of Drosophila. Curr Opin Neurobiol 20: 281-287.

Pennetier C, Warren B, Dabiré KR, Russell IJ, Gibson G 2010. "Singing on the wing" as a mechanism for species recognition in the malarial mosquito Anopheles gambiae. Curr Biol 20: 131-136.

Pires HHR, Lorenzo MG, Lazzari CR, Diotaiuti L, Manrique G 2004. The sexual behaviour of Panstrongylus megistus (Hemiptera : Reduviidae): an experimental study. Mem Inst Oswaldo Cruz 99: 295-300.

Popham EJ, Parr MJ, Chowdhury V 1978. Specific differences in tsetse fly sounds and their behavioral significance. Experientia 34: $1152-1154$

Ritchie MG 2007. Sexual selection and speciation. Annu Rev Ecol Evol Syst 38: 79-102.

Ritchie MG, Townhill RM, Hoikkala A 1998. Female preference for fly song: playback experiments confirm target of sexual selection. Anim Behav 59: 713-717.

Robert D, Miles RN, Hoy RR 1999. Tympanal hearing in the sarcophagid parasitoid fly Emblemasoma sp.: the biomechanics of directional hearing. $J$ Exp Biol 202: 1865-1876.

Roces F, Manrique G 1996. Different stridulatory vibrations during sexual behaviour and disturbance in the blood-sucking bug Triatoma infestans (Hemiptera: Reduviidae). J Insect Physiol 42: 231-238.

Rudrauf JM 1977. Comportement acoustico-sexuel d'une glossine, Glosssina fuscipes fuscipes Newstead, 1910. Ann Zoolet Ecol Anim 9: 389-406.

Ryner LC, Goodwin SF, Castrillon DH, Anand A, Villella A, Baker BS, Hall JC, Taylor BJ, Wasserman SA 1996. Control of male sexual behavior and sexual orientation in Drosophila by the fruitless gene. Cell 87: 1079-1089.

Saini RK 1981a. The pattern of sound production by the tsetse fly Glossina morsitans morsitans Westwood, 1850 (Diptera, Glossinidae). Insect Sci Appl 1: 167-169.

Saini RK 1981b. Communication by sound in tsetse. Span 24: 98-99.

Saini RK 1983. Sound production associated with feeding behavior of the tsetse, Glossina m. morsitans. Entomol Exp Appl 34: 1-8.

Saini RK 1984. Acoustic emissions of tsetse. Insect Sci Appl 5: 341-344.

Saini RK 1985. Sound production associated with sexual behavior of the tsetse, Glossina morsitans morsitans. Insect Sci Appl 6: 637-644.

Sant'Anna MR, Alexander B, Bates PA, Dillon RJ 2008. Gene silencing in phlebotomine sand flies: Xanthine dehydrogenase knock down by dsRNA microinjections. Insect Biochem Mol Biol 38: 652-660.

Sawadogo SP, Costantini C, Pennetier C, Diabaté A, Gibson G, Dabiré KR 2013. Differences in timing of mating swarms in sym- patric populations of Anopheles coluzzii and Anopheles gambiae s.s. (formerly An. gambiae $\mathrm{M}$ and $\mathrm{S}$ molecular forms) in Burkina Faso, West Africa. Parasit Vectors 6: 275.

Schilman PE, Lazzari CR, Manrique G 2001. Comparison of disturbance stridulations in five species of triatominae bugs. Acta Trop 79: $171-178$.

Schofield CJ 1977. Sound production in some triatomine bugs. Physiol Entomol 2: 43-52.

Seeley TD, Tautz J 2001. Worker piping in honey bee swarms and its role in preparing for liftoff. $J$ Comp Physiol [A] 187: 667-676.

Simard F, Ayala D, Kamdem GC, Pombi M, Etouna J, Ose K, Fotsing JM, Fontenille D, Besansky NJ, Costantini C 2009. Ecological niche partitioning between Anopheles gambiae molecular forms in Cameroon: the ecological side of speciation. $B M C$ Ecol 9: 17.

Souza NA, Andrade-Coelho CA, Vigoder FM, Ward RD, Peixoto AA 2008. Reproductive isolation between sympatric and allopatric Brazilian populations of Lutzomyia longipalpis s.l. (Diptera : Psychodidae). Mem Inst Oswaldo Cruz 103: 216-219.

Stone CM, Tuten HC, Dobson SL 2013. Determinants of male Aedes aegypti and Aedes polynesiensis (Diptera: Culicidae) response to sound: efficacy and considerations for use of sound traps in the field. J Med Entomol 50: 723-730.

Tauber E, Eberl DF 2003. Acoustic communication in Drosophila. Behav Processes 64: 197-210

Tripet F, Clegg S, Elnaiem D-E, Ward RD 2009. Cooperative bloodfeeding and the function and implications of feeding aggregations in the sand fly, Lutzomyia longipalpis (Diptera: Psychodidae). PLoS Negl Trop Dis 3: e503.

Tripet F, Dolo G, Traore S, Lanzaro GC 2004. The "wingbeat hypothesis" of reproductive isolation between members of the Anopheles gambiae complex (Diptera: Culicidae) does not fly. $J$ Med Entomol 41: 375-384.

Tuck EJ, Windmill JFC, Robert D 2009. Hearing in tsetse flies? Morphology and mechanics of a putative auditory organ. Bull Entomol Res 99: 107-119.

Vigoder FM, Araki AS, Bauzer LGSR, Souza NA, Brazil RP, Peixoto AA 2010a. Lovesongs and period gene polymorphisms indicate Lutzomyia cruzi (Mangabeira, 1938) as a sibling species of the Lutzomyia longipalpis (Lutz and Neiva, 1912) complex. Infect Genet Evol 10: 734-739.

Vigoder FM, Souza NA, Peixoto AA 2010b. Copulatory courtship song in Lutzomyia migonei (Diptera: Psychodidae). Mem Inst Oswaldo Cruz 105: 1065-1067.

Vigoder FM, Souza NA, Peixoto AA 2011. Acoustic signals in the sand fly Lutzomyia (Nyssomyia) intermedia (Diptera: Psychodidae). Parasit Vectors 4: 76.

von Philipsborn AC, Liu T, Yu JY, Masser C, Bidaye SS, Dickson BJ 2011. Neuronal control of Drosophila courtship song. Neuron 69: 509-522.

Ward RD, Phillips A, Burnet B, Marcondes CB 1988. The Lutzomyia longipalpis complex: reproduction and distribution. In $\mathrm{MW}$ Service (ed.), Biosystematics of haematophagous insects, Oxford University Press, Oxford, p. 258-269.

Warren B, Gibson G, Russell IJ 2009. Sex recognition through midflight mating duets in Culex mosquitoes is mediated by acoustic distortion. Curr Biol 19: 485-491.

Yack JE 2004. The structure and function of auditory chordotonal organs in insects. Microsc Res Tech 63: 315-337. 